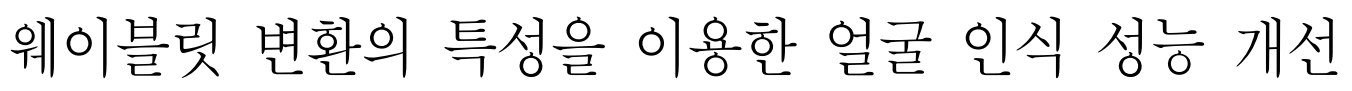

\title{
Performance Improvement of the Face Recognition Using the Properties of Wavelet Transform
}

\author{
박경준 ${ }^{*}$, 서석용 ${ }^{* *}$, 고형화 ${ }^{* *}$ \\ Kyung-Jun Park*, Seok-Yong Seo**, and Hyung-Hwa Koh ${ }^{* * *}$ \\ 요 약
}

본 논문에서는 웨이블릿 변환의 특성을 이용한 얼굴인식 방법을 제안하여 인식성능 향상에 관한 연구를 진 행하였다. 사용한 이산 웨이블릿 변환은 모웨이블릿의 특징과 비슷한 Daubechies D4 필터이다. 웨이블릿 변환 영역 중 LL 대역의 데이터만을 이용할 경우 원본 데이터에 비하여 크기가 줄어들게 되어 인식과정의 속도와 메모리 사용량을 줄일 수 있게 된다. 또한 2차원 데이터의 변형없이 손실을 줄여 인식률을 향상시키기 위하여 2 차원 LDA 방법을 적용하였다. 그리고 여기서 얻은 특징벡터를 이용하여 SVM을 수행하도록 하였다. 실험은 Matlab 프로그램을 통하여 ORL 얼굴 데이터베이스와 Yale 얼굴 데이터베이스를 이용하여 실험을 하였고 기존 의 방법들과 인식률과 수행시간을 비교를 함으로써 제안한 방법의 우수성을 입증하였다.

Abstract

This paper proposed face recognition methods about performance improvement of the face recognition using the properties of wavelet transform. Using discrete wavelet transform is Daubechies D4 filter that is similar to mother wavelet transform. For discrete wavelet transform method, In this case, by using LL subband only we can reduce processing time and amount of memory in recognition processing. To improve recognition ratio without further loss of 2 dimensional data changing, We applies 2D LDA. We perform SVM training algorithm to the feature vector obtained by 2D LDA. Experiment is performed using ORL database set and Yale database set by Matlab program. Test result shows that proposed method is superior to existence methods in recognition rate and performance time.

Key words : Face Recognition, Wavelet Transform, SVM

\section{I. 서 론}

현대사회가 디지털 사회로 전환되어감에 따라 정 보의 저장 및 처리도 여러 디지털화된 기술들이 적용 되어 발달되고 있다. 이러한 기술 중에 가장 대표적
인 방법이 암호화 기법일 것이다. 암호화 기술들은 암호화키의 분실 위험과 복제나 위·변조 등의 위험성 또한 같이 존재하고 있다. 이 같은 문제들로 인하여 암호화 보안키의 관리나 해킹 등의 위험으로부터 디 지털 정보의 접근과 보호에 많은 노력을 기울이고 있

\footnotetext{
* 마크애니(MarkAny. co. Ltd.)

** 경민대학교 정보통신과(Dept. of Information Communication, Kyungmin College)

*** 광운대학교 전자통신공학과(Dept. of Electronics and Communication Eng., Kwangwoon University)

· 제1저자 (First Author) : 박경준(Kyung-Jun Park, tel : +82-2-940-5137, e-maiil : red2000@kw.ac.kr)

· 접수일자 : 2013년 8월 30일 · 심사(수정)일자 : 2013년 8월 30일 (수정일자 : 2013년 12월 16일) · 게재일자 : 2013년 12월 30일 http://dx.doi.org/10.12673/jkoni.2013.17.6.726
} 
다. 이런 위험적인 요소를 줄이고 복잡한 절차 없이 정보의 접근 및 보호를 할 수 있는 분야로 주목받고 있는 것이 생체 인식 시스템이다. 생체 정보는 자연 적이고 강제성이 없이 사용할 수 있는 시스템으로 개 인 고유마다의 특징이 다르기 때문에 데이터 중복의 확률이 적어, 고유의 생체정보를 이용한 인증을 통하 여 중요 정보의 보호에 이용할 수 있다는 장점을 가 진다. 생체정보를 이용한 개인의 인증 방법에는 지 문, 홍채, 음성, 혈관, DNA, 서명(Signature) 등 여러 가지 방법들이 있다. 지문이나 홍체, 혈관 등의 생체 인증 시스템에서는 스캐너 등의 별도의 장비가 필요 하며, 스캐너에 생체의 특정부분을 접촉시키는 동작 이 필요하게 된다. 음성인식 또한 특이의 말이나 단 어를 통하여 인증을 필요로 하게 된다. 이에 반해 얼 굴 인식 시스템의 경우 일반적인 비디오 카메라를 이 용하여 행동이나 접촉 등의 행동을 필요로 하지 않 는 비접촉식 시스템으로 인증을 통하여 정보의 접근 이나 보호가 가능하게 되어있다. 그러나, 이러한 시 스템도 조명 위치, 카메라의 위치, 표정의 변화, 안경 이나 모자 등에 의한 얼굴의 가림, 노화 등의 제약사 항이 존재하여 인식에 어려움이 많다. 기술의 발달과 다각적인 방향에서 연구한 결과 많은 인식률의 개선 을 보였으나 여전히 인식률 개선에 관한 효과적인 방 법에 관한 연구가 진행되었다[1][2].

현대의 얼굴인식을 위한 기술은 무인경비 및 출입 통제 등의 보안 시스템, 신원 확인, 범죄 예방 및 해 결 등의 보안 분야뿐만 아니라 우리 사회에 한층 더 다가와 있는 전자 주민증 또는 전자 여권과 같은 신 분증에도 생체정보를 삽입할 수 있어 더 밀접하게 느 낄 수 있다. 또한 디지털 엔터테인먼트 시스템에도 적용되어 관상, 닮은꼴 연예인 찾기, 디지털 카메라 의 특정 표정 중 촬영 등 여러 상업적인 분야에서 활 용되고 있다. 이러한 얼굴인식 시스템의 활용은 산업 화에 따라 높은 신뢰성이 요구되고 있다.

본 논문에서는 웨이블릿 변환의 특징을 이용한 얼 굴인식 방법을 제안하여 인식률을 향상시키고자 하 였다. 웨이블릿 변환에는 이산 웨이블릿 변환 방법을 이용한 얼굴인식 방법을 제안하였다. 이산 웨이블릿 변환은 통하여 에너지의 대부분이 집중되어 있는 $\mathrm{LL}$ 대역을 이용하여 영상의 크기를 줄이고, 분산을 최대
화 할 수 있는 영역의 데이터를 이용함으로써 인식률 의 향상을 꾀하였고, 2 차원의 $\mathrm{LDA}$ 를 수행하도록 하 여 1차원 벡터로의 변환 과정이 필요 없으며, 이로 인해 손실이 줄어들게 되어 인식률을 향상 시킬 수 있도록 하였다. 또 클래스간의 분산과 클래스내의 분 산도 고려하기 때문에 표정이나 조명의 변화에 강인 한 얼굴인식 시스템을 구성하도록 하였다. 마지막으 로 최적화된 분류기라 할 수 있는 SVM을 이용하여 고유의 특징 벡터를 사용하여 다중 SVM 분류를 수 행하도록 하였다. 이로써 학습 시간을 단축시키고, 인식률의 향상을 이루고자 하였다.

본 논문의 구성은 2 장에서는 얼굴 인식방법의 알 고리즘에 대한 분석을 하고, 3 장에서는 본 논문에서 사용한 웨이블릿 변환을 이용한 얼굴인식 방법을 제 안하였다. 4장에서는 실험을 통하여 제안한 알고리 즘의 우수성을 기존의 알고리즘과 비교를 통하여 확 인하였고, 5장에서 결론을 이끌어 내었다.

\section{II. 얼굴 인식 방법}

Kanade에 의해 1973년 얼굴의 기하학적 특징에 기 반 한 최초의 얼굴인식 시스템을 제안한 이후로 얼굴 인식의 기술이 발달됨에 따라 인식률 향상을 위하여 여러 방식의 얼굴 인식 방법들이 제안되고 있다. 얼 굴 인식에는 엄밀히 구분하자면 얼굴 검출과 얼굴 인 식으로 구분되어진다. 얼굴 검출에 사용되는 방법들 은 얼굴 인식에서도 동일하게 사용되어지기도 한다.

얼굴인식 방법은 통계학적인 분석에 의한 방법, 특징기반에 의한 인식방법, 외형적 기반에 의해 분류 하는 방법 등으로 분류된다. 대표적인 통계학적 분석 방법으로는 주성분 분석법( $\mathrm{PCA})$, 선형판별 분석법 (LDA), 독립성분분석법(ICA), LFA(Local Feature Analysis) 등이 있다. Turk는 1991년 주성분 분석법 (PCA)을 적용한 얼굴인식 방법을 제안하였다[3]. Belhumeur는 PCA와 LDA를 결합한 방법을 이용한 얼굴인식 방법을 제안하여 클래스간의 판별 능력을 향상시켰다[4]. Yang은 영상의 공분산 행렬에 PCA 기법을 적용한 2D PCA 방법을 제안하여 계산량을 줄이고 인식률을 향상시켰다[5]. Li는 영상의 공분산 
행렬에 $\mathrm{LDA}$ 를 적용한 2D LDA를 제안하여 2D PCA 보다 인식률을 향상시켰다[6]. 또 얼굴의 눈, 코 입 등 의 특징점을 찾아 기하학적인 형태를 비교하여 인식 하는 방법(AAM: Active Appearance Model)있다. Edward가 제안한 $\mathrm{AAM}$ 은 Cootes 에 의해 확장되어 발전되어 왔다[7]. AAM은 변형 가능한 2차원 물체의 검출에 효과적인 방법으로 공간 좌표에서 특징점을 이용하여 얼굴 검출 및 인식에 이용한다. 이 때 사용 하는 정보가 2차원 공간상의 특징점 집단과 그에 연 관된 픽셀들의 명암도 정보이다. 이는 공간 좌표상의 특징점 집단으로부터 볼록 외피(Convex hull) 알고리 즘을 적용하여 내부의 픽셀들만을 이용한다.

특정 모양의 템플릿을 찾아 비교를 통해서 각 구 성 성분의 위치와 거리를 이용한 템플릿 매칭 방법 이 있다. 또 은닉 마코프 모델(HMM)을 이용한 방법 이 있다. $\mathrm{HMM}$ 은 각 상태간의 전이확률을 가지는 유 한상태 기계로, 각 상태는 직접 관측이 불가능하며, 각 상태들로부터 일정확률로 관측할 수 있는 관측 심 벌을 통하여 상태를 추정하는 방법이다. 이 외에도 신경회로망을 이용한 방법, 퍼지를 이용한 방법, 유 전자 알고리즘을 이용한 방법, 서포트 벡터 머신 (Support Vector Machine: SVM) 분류기를 이용한 방 법 등이 알려져 있다[2].

이 장에서는 가장 대표적인 얼굴인식 방법이라 할 수 있는 주성분 분석법 $(\mathrm{PCA})$ 과 피셔의 판별식 (Fisher's Discriminant)을 사용하는 선형판별 분석법 (LDA)과 성능이 뛰어나 많이 활용되고 있는 서포트 벡터 머신(SVM) 에 대하여 소개한다.

\section{2-1 주성분 분석법 (Principal Component Analysis: PCA)}

주성분 분석법은 고차원 입력벡터를 저차원의 벡 터로 표현하여 몇 개의 주성분 값으로 나타내는 방식 으로, 각 주성분이 가지는 분산의 크기를 중요도 순 으로 정렬하면 처음 몇 개의 주성분이 원 정보의 총 분산이 가능한 많은 에너지를 보유하도록 하여 차원 을 축소시키는 방법이다. $\mathrm{PCA}$ 는 데이터의 평균과 표 준편차, 공분산의 통계적 성질을 이용한 방법으로 Karhunen-Loeve (K-L)의 변환 또는 Hotelling 변환이 라고 불리기도 한다. 데이터의 분산을 큰 값을 가지
는 몇 개의 고유 얼굴(Eigen face)이라 불리는 고유벡 터 축으로 선형 투영시켜 차원을 축소하는 방법으로 클래스의 차원을 축소시켜 간단하게 표현 할 수 있어 많이 사용되어지는 방법이다.

1987년 Sirovich와 Kirby에 의해 얼굴영상의 효과 적인 차원 축소 표현을 위하여 $\mathrm{PCA}$ 를 적용한 방법을 처음으로 제안하였다[8]. 1991년에는 Turk와 Pentland 에 의해 발전된 형태의 고유얼굴(Eigenfaces) 방법을 제안하였다[3]. 주성분 분석법(PCA)을 이용한 얼굴인 식 방법은 얼굴 영상을 벡터로 표현하고 이를 이용하 여 공분산 행렬을 구한다. 이 공분산 행렬을 이용하 여 고유값과 고유벡터를 구하고, 가장 큰 순서로 정 렬된 고유값에 해당하는 고유벡터를 선택한다. 이 고 유벡터가 얼굴 영상의 특징을 나타내는 기저 벡터가 된다. PCA 변환했을 때 주성분의 최대 수는 입력된 영상의 차원과 같으며 고유값은 지수함수와 같이 급 속히 감소하는 형태를 가지므로 마지막의 몇몇 주성 분들이 없어도 원영상과의 차이가 크지 않아 생략 가 능하다. 인식을 위해 입력된 얼굴영상을 선형 변환하 여 얻은 특징 벡터를 학습을 통해 구해놓은 특징 벡 터들과의 유사도를 비교함으로써 인식을 수행하는 방법이다.

\section{2-2 선형 판별 분석법 (Linear Discriminant Analysis: LDA)}

$\mathrm{LDA}$ 는 통계적 성질을 이용한 차원 축소 기법 중 하나로 MDF(Most Discriminant Feature)라고 불리기도 한다. 이 방법은 적용에 있어서 Fisher의 판별식을 이 용하였기 때문에 FLD(Fisher's Lenear Discriminent)라 고도 불린다. LDA 방법은 얼굴의 국부적 특징을 다 른 얼굴로부터 잘 분리해 표현할 수 있는 방법이다. $\mathrm{PCA}$ 방법의 문제점중 하나는 영상의 변화가 객체의 변화로 인한 것인지 아니면 그 이외의 조명이나 표정 변화 등의 환경변화 때문인지를 구분하지 못한다. 이 는 PCA 방법은 선형 변환된 특징 공간에서 모든 데 이터들의 분산을 최대화 하는 투영벡터를 설정하지 만, LDA 방법은 클래스 정보를 이용하여 클래스간의 분산은 최대로 하면서 동시에 클래스 내의 분산은 최 소화 하는 방향으로 투영벡터를 성정하기 때문에 클 래스간의 판별에 더 효과적이다. LDA 방법은 클래스 
(객체)의 변화를 감지하여 이를 극복하고자 하였다. 따라서 선형 판별 분석법(LDA)는 주성분 분석법 $(\mathrm{PCA})$ 에 비하여 조명이나 표정의 변화 등에 강인한 특성을 가진다. Belhumeur에 의해 고유얼굴 (Eigenfaces)과 대응되는 피셔얼굴(Fisherfaces)을 이용 하기도 하였다. $\mathrm{PCA}$ 는 모든 데이터의 분산을 최대화 하기 때문에 두 클래스의 분류가 어렵지만 LDA는 각 클래스내의 분산을 최소화하고 클래스 간의 분산을 최대화 하는 투영벡터를 설정하기 때문에 구분이 가 능하다.

2차원 선형판별 분석법(2D LDA)은 2차원 데이터 의 차원의 변화 없이 사용할 수 있는 방법으로 입력 영상의 공분산 행렬을 직접 이용한다[9][10]. Li와 Xiong 는 2 차원 $\mathrm{LDA}$ 을 제안하여 인식률이 2차원 PCA 방법보다 우수한 성능을 보였다[11][12]. 2차원 영상 자체를 행렬식으로 이용하여 영상의 공분산 행 렬을 직접 구하므로 기존의 $\mathrm{LDA}$ 에서 문제가 되었던 클래스 내의 공분산 행렬이 특이 행렬이 되는 문제를 해결 할 수 있었다. 이것은 LDA 방법을 사용하는데 있어서 취약점으로 작은 샘플의 크기로 인해서 발생 한다. 샘플의 차원보다 샘플의 크기가 작으면 발생하 는 문제로 $\mathrm{SSS}$ (Small Sample Size)문제라 불린다. $\mathrm{PCA}$ 와 비교해서도 작은 샘플의 크기(SSS) 문제에 더 취약하고, LDA가 추정해야할 파라미터가 PCA보다 많아서 많은 훈련 샘플들을 필요로 한다.

2차원 LDA에서는 투영 벡터가 중요한 의미를 지 니기 위해서는 판별기준이 필요하다. Turk 등은 투영 된 샘플들의 전체 공분산 행렬의 모든 대각 요소들의 값을 합하여 특징을 나타내었다. 이것은 클래스 간 전체 공분산을 최대화하며, 동시에 클래스 내의 전체 공분산을 최소로 만드는 투영벡터를 선택한다. 일반 적인 2차원 선형판별 분석법은 앞에서 수행하였던 $\mathrm{LDA}$ 방법의 순서와 같다.

\section{2-3 서포트 벡터 머신 (Support Vector Machine)}

SVM은 V. Vapnik에 의해 1970년대 말에 제안되었 으나 주목받지 못하다가 1990년대 인식 분야에 도입 되어 우수한 능력을 입증받기 시작하여 패턴 인식 분 야에서 주목받는 식별방법이다. SVM은 다항식, 방사 기저 함수, 다중 퍼셉트론 분류기의 대안적인 학습
방법으로, 패턴을 고차원 특징공간으로 사상시킬 수 있다는 점과 최적의 대역적인 식별이 가능하다는 특 징을 가진다. 또 네트워크의 가중치는 비볼록 (Non-convex), 제약조건이 없는 최소화 문제를 해결 하여 구하는 일반적인 신경망과는 달리 선형부등 조 건을 가진 $\mathrm{QP}(\mathrm{Quadratic}$ Programming) 문제를 해결함 으로써 얻는다. SVM은 기존의 패턴분류기법들이 경 험적인 위험을 최소화(Empirical Risk Minimization)하 는데 반해, 구조적 위험을 최소화(Structural Risk Minimization)하여 일반화된 오차를 감소시키는 방법 으로 이에 기반한 최적의 분리 경계면(Optimal Hyperplane)을 찾는 이진 분류 기법이다. 여기서 경험 적 위험의 최소화란 훈련 집단의 수행도를 최적화 하 려는 것을 의미하고, 구조적 위험의 최소화란 고정되 어 있지만 확인되지 않은 확률분포를 가진 데이터를 잘못 분류하는 확률을 최소화 하는 것을 의미한다.

\section{2-3-1 선형 SVM}

$\mathrm{SVM}$ 은 기본적으로 두 클래스의 효율적 분리를 목 적으로 하는 이진 분류기이다. 이 두 클래스를 분리 하는 분리경계면(Hyperplane)은 무수히 많이 존재한 다. 이때 분리경계면에 가장 가까이에 위치한 데이터 를 서포트 벡터라 하며, 분리경계면에서 이 서포트 벡터까지의 최소거리를 마진이라 한다. 최적의 분리 경계면은 두 클래스의 마진을 최대화하여 클래스의 구분을 최적화 하는 것이다. 이 최적의 경계 분리면 을 찾기 위해 마진이 최대가 되도록 하는 서포트 벡 터를 찾는 과정이 SVM 학습이다. 그림 1의 두 범주 에 속하는 $\mathrm{N}$ 개의 점들 $x_{i}$ 가 $y_{i} \in\{1,-1\}$ 로 분리 되어 진다고 가정할 경우 분리경계면들은 벡터의 내 적으로 표현하며 $\mathrm{w}$ 는 경계면과 직교하는 가중치 벡 터로 나타내고, $\mathrm{b}$ 는 기준값(threshold)이다.

$$
\begin{aligned}
& w_{i}^{T} x_{i}+b \geq 1, \quad \text { for } \quad y_{i}=1 \\
& w^{T} x_{i}+b \leq-1, \text { for } \quad y_{i}=-1
\end{aligned}
$$

이 식을 하나의 식으로 결합하면 다음의 식과 같다.

$$
y_{i}\left(w^{T} x_{i}+b\right)-1 \geq 0, \forall i=(1, \ldots, N)
$$




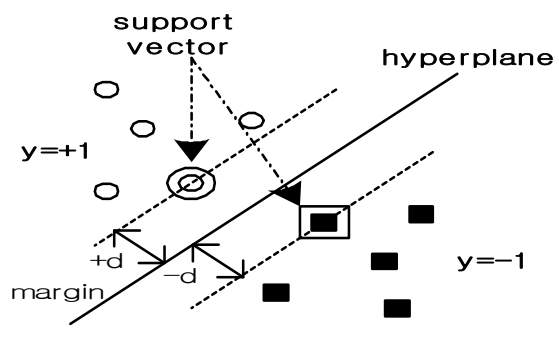

그림 1. SVM의 hyperplane 분리 예

Fig. 1. Example of Hyperplane in SVM.

마진 $\quad d=\frac{1}{\|w\|}$ 으로 최대 마진(Margin)은 $\operatorname{Max} \frac{2}{\|w\|}$ 이 되며, 이는 $\|w\|^{2}$ 을 최소화함으 로써 최대 마진을 가지는 최적의 분리경계면을 찾을 수 있다.

$$
\begin{aligned}
& \text { Minimize }: J(\mathrm{w})=\frac{\|\mathrm{w}\|^{2}}{2} \\
& y_{i}\left(w^{T} x_{i}+b\right)-1 \geq 0, \quad \forall i=(1, \ldots, N)
\end{aligned}
$$

SVM의 최적화 문제를 라그랑제(Lagrange) 함수로 표현하면 다음과 같다.

$$
\begin{aligned}
& J(w, b, a)=\frac{1}{2}\|w\|^{2}-\sum_{i=1}^{N} \alpha_{i}\left(y_{i} \cdot\left[w^{T} x_{i}+b\right]-1\right) \\
& \text { where, } \alpha_{i} \geq 0, \quad i=1,2, \cdots, N
\end{aligned}
$$

여기서 $\alpha_{i}$ 는 라그랑제 승수이다.

\section{2-3-2 비선형 SVM}

선형적 분리가 불가능 한 경우 슬랙 변수(slack variable)를 제약조건에 포함시켜 오분류를 허용함으 로써 최적의 분리 영역을 선형적으로 만들 수 있다. 선형분리가 불가능한 경우 비선형 변환 함수를 이용 하여 고차원의 공간으로 사상(Mapping) 시키면 선형 분리가 가능하게 된다. 선형분리가 불가능한 1 차원 의 데이터를 변환 함수를 이용하여 2 차원의 데이터 로 사상하여 분리 가능 하려면 사상된 공간에서도 원 공간에서의 거리 관계를 어느 정도 보존할 필요가 있
으므로 사상 함수를 이용하여 커널 함수(Kernel function)를 다음의 식(7)과 같이 정의한다.

$$
K\left(x, x^{\prime}\right)=\phi(x) \cdot \phi\left(x^{\prime}\right)=\phi(x)^{T} \phi\left(x^{\prime}\right)
$$

위의 식(7)과 같이 사상된 공간에서의 식별을 위하 여 구체적인 사상함수를 설정하지 않고도 식별 함수 를 구현 할 수 있는데, 이처럼 사상함수에 대한 계산 을 회피하는 방법을 커널 트릭이라 한다. 커널 트릭 은 커널 함수가 주어진 경우에만 유용하다.

\section{2-3-3 다중 클래스 SVM}

얼굴 인식의 경우 많은 얼굴 클래스를 사용하기 때문에 이진 분류기로만 사용하기에는 부족함이 있 다. 이를 극복하기 위하여 다중 클래스 SVM 을 이용 한다. 다중 클래스 SVM 방법에는 크게 두 가지의 접 근 방법이 있다. 하나는 일대일(one-to-one) SVM 방법 과 또 다른 방법은 일대다(one-to-many) SVM 방법이 있다. 일대일 방법은 $(\mathrm{K}-1) \times \mathrm{K}$ 개의 다중 분류모델을 구성하여 가장 많이 결과로 출력되어진 클래스가 해 당 클래스로 분류하는 방법이고, 일대다 방법은 $\mathrm{K}$ 개 의 클래스를 분류하기 위하여 $\mathrm{K}$ 개의 이중 분류 모델 을 구성하고, SVM 결과값 중 최대값을 해당 클래스 로 분류하는 방법이다.

\section{III. 제안하는 얼굴 인식 방법}

제안한 얼굴 인식 시스템에 대한 전체적인 블록도 는 그림 2에 나타내었다. 먼저 훈련 얼굴 영상을 입 력받아 웨이블릿 변환을 수행한다. Haar 필터보다 성 능이 우수하고 모웨이블릿에 근접한 Daubechies D4 필터를 이용하여 이산 웨이블릿 변환을 수행한다. 그 림 3 는 웨이블릿 변환의 예를 보여주고 있다. 변환된 데이터 중에서 LL 대역의 데이터를 이용하여 얼굴 인식 데이터로 사용하였다. LL대역은 에너지의 집중 도가 높고, 원영상과 비슷한 영상을 표현하고 있기 때문에 LL 대역의 데이터만으로도 원영상의 복원이 가능하다. 또한 LL 대역의 데이터를 이용할 경우 영 


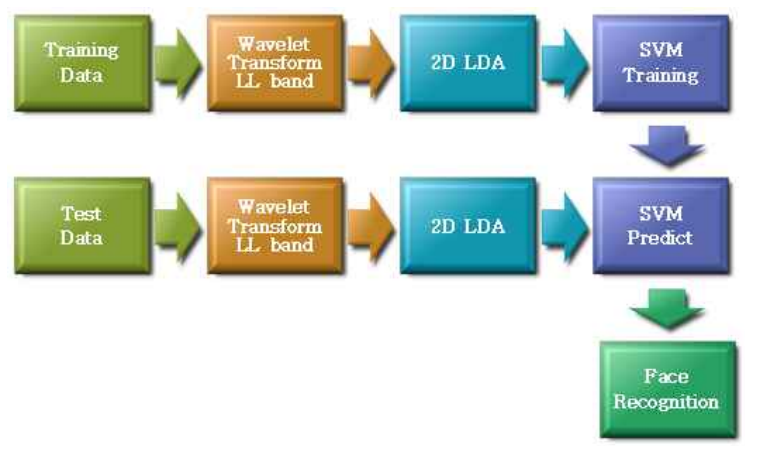

그림 2. 제안한 방법의 블록도

Fig. 2. Block diagram of the proposed method.
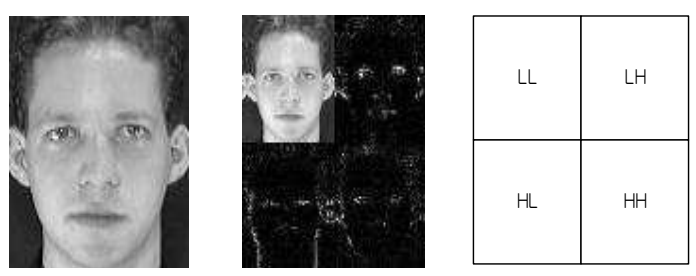

그림 3. 이산 웨이블릿 변환 예

Fig. 3. Example of discrete wavelet transform.

상의 크기가 축소되어 얼굴인식에서 처리해야할 데 이터양이 줄게 되어 처리 시간의 단축을 가져올 수 있게 된다. 또한 줄어든 데이터 양으로 인하여 메모 리의 효율적인 이용이 가능하게 된다. 또한 에너지가 집중된 영역으로 분산의 최대화를 통한통계적인 인 식방법에서는 인식률 향상을 위한 효과적인 방법인 $\mathrm{LDA}$ 와 SVM을 계속하여 적용하였다. D4 필터의 스 케일링 함수 계수(Scaling function coefficient)는 다 음의 식과 같다.

$h_{0}=\frac{1+\sqrt{3}}{4 \sqrt{2}}, h_{1}=\frac{3+\sqrt{3}}{4 \sqrt{2}}, h_{2}=\frac{3-\sqrt{3}}{4 \sqrt{2}}, h_{3}=\frac{1-\sqrt{3}}{4 \sqrt{2}}$

웨이블릿 변환식은 다음과 같다.

$a_{i}=h_{0} s_{2 i}+h_{1} s_{2 i+1}+h_{2} s_{2 i+2}+h_{3} s_{2 i+3}$

$a[i]=h_{0} s[2 i]+h_{1} s[2 i+1]+h_{2} s[2 i+2]+h_{3} s_{[2 i+3]}$

D4 필터의 웨이블릿 함수 계수(Wavelet function coefficient)는 다음의 식과 같이 스케일일 함수 계수 를 이용한다.

$$
g_{0}=h_{3} \quad, \quad g_{1=}-h_{2} \quad, \quad g_{2}=h_{1} \quad, \quad g_{3}=-h_{0}
$$

역 웨이블릿 변환식은 다음과 같다.

$$
\begin{aligned}
& c_{i}=g_{0} s_{2 i}+g_{1} s_{2 i+1}+g_{2} s_{2 i+2}+g_{3} s_{2 i+3} \\
& c[i]=g_{0} s[2 i]+g_{1} s[2 i+1]+g_{2} s[2 i+2]+g_{3} s_{[2 i+3]}
\end{aligned}
$$

따라서 본 논문에서 이용한 Daubechies D4 필터의 계수는 다음과 같다

$$
\begin{aligned}
\text { D4 wavelet }=\{ & -0.1830127,-0.3169873,1.1830127, \\
& -0.6830127\}
\end{aligned}
$$

먼저, 학습 과정은 웨이블릿 변환된 LL 대역의 데 이터를 입력 데이터로 이용하여 2차원 LDA를 수행 한다. 2 차원 $\mathrm{LDA}$ 는 입력된 훈련 영상들의 전체 평균 값과 클래스내의 평균값을 계산한다. 이를 이용하여 클래스내의 분산과 클래스 간의 분산을 고려하여 분 산이 최대화되는 고유 특징벡터를 구한다. 2 차원 $\mathrm{LDA}$ 의 경우는 입력된 2차원 데이터의 변형이 없이 바로 이용하기 때문에 벡터의 변환과정이 없어 손실 을 줄일 수 있어 1차원 LDA에 비하여 인식률을 높일 수 있다. 2 차원 $\mathrm{LDA}$ 를 수행하여 얻은 고유의 특징 데이터 중 가장 큰 값들을 취하여 SVM 학습을 수행 한다. SVM 분류기는 현재 최적의 효율을 보일 수 있 는 분류기로서 SVM 학습의 경우 해당 클래스에 속 하면 +1 의 값을, 다른 클래스에 해당하는 경우 -1 의 값을 가진다. 이때 SVM은 일대일 다중 분류기 (Multi-class classifier)를 이용한다. SVM 수행의 경우 단순하면서 속도가 빠른 선형 분류 함수를 이용하여 SVM을 수행하도록 한다. SVM 학습의 결과 모델을 가지고 얼굴 인식의 과정을 수행한다.

다음으로, 인식 과정은 테스트 얼굴 데이터가 입 력되어지면 훈련 과정에서 사용하였던 방법들과 동 일한 과정을 거치게 된다. 먼저 Daubechies D4 필터 를 이용하여 이산 웨이블릿 변환을 수행하여 LL대역 의 데이터만을 취하게 된다. 이 데이터를 앞의 훈련 과정에서 2차원 $\mathrm{LDA}$ 을 수행하여 얻은 고유의 특징 벡터를 이용하여 차원을 축소시킨다. 이 결과 데이터 
를 SVM 학습과정에서 얻은 SVM 모델을 이용하여 SVM 예측을 수행하여 입력된 영상이 어느 클래스에 속하는지를 예측하게 된다.

\section{IV. 실험 및 결과}

\section{4-1 실험 환경}

본 논문의 실험 환경은 Intel Core2Duo CPU를 이 용한 PC에서 Matlab 프로그램을 이용하여 기존의 방 법들과 제안한 방법들의 실험을 수행하였다. 본 논문 에서 사용된 SVM 프로그램은 대만의 Chih-Jen Lin이 개발한 LibSVM( Library of support vector machine)을 이용하여 SVM 분류기로 사용하였다[13].

실험에 사용한 얼굴의 데이터는 객관적인 비교 평 가를 위하여 인식 평가에 많이 사용되고 있는 ORL 얼굴 데이터와 Yale 얼굴 데이터베이스를 이용하여 실험을 수행하였다. ORL 얼굴데이터는 영국의 캠브 리지에 있는 AT\&T의 Olivetti Research Laboratory에 서 1992년 4월부터 1994년 4월까지 2년간 40명의 사 람을 대상으로 조명 위치와 얼굴 표정, 안경 착용, 얼 굴의 방향 등을 서로 달리해서 다양한 조건의 구성으 로 각 개인당 10 장의 서로 다른 얼굴영상으로 구성하 여 총 400 개의 얼굴영상으로 구성되어 있다[14]. 영 상의 구성은 그레이 레벨의 영상으로 $112 \times 92$ 크기의 얼굴영상으로 구성되어 있으며, 약 $10 \%$ 정도의 크기 변화와 약 $20^{\circ}$ 정도의 회전과 기울기를 가지는 정면 얼굴로 구성된다. 이러한 다양한 구성으로 인하여 얼 굴 인식의 성능 평가에 많이 사용되고 있는 얼굴 영 상 데이터베이스이다.

Yale 얼굴데이터의 경우 미국의 Yale 대학에서 획 득한 영상으로 다양한 위치의 조명과 서로 다른 표정 을 가지고 있는 영상으로 구성되어 있다. 15 명의 서 로 다른 사람으로 구성되어 있으며 개인당 11 장의 얼 굴영상이 다양한 표정과 조명 환경을 가지고 있으며, 총 165 개의 얼굴 영상으로 구성되어 있다[15]. 실험 에서 사용한 영상의 크기는 $64 \times 64$ 크기의 그레이 레 벨의 영상이다.

실험에서는 훈련 영상으로 ORL 영상데이터의 경
우는 각 사람당(클래스:Class) 5장을 총 200장을 사용 하였으며 Yale 영상데이터는 각 사람당 6장을 총 90 장을 훈련에 사용하였다. 인식을 위한 테스트 영상으 로는 ORL 영상데이터는 각 사람당 5 장의 영상을 총 200 장을 사용하였으며, Yale 영상데이터는 각사람당 5 장을 총 75 장의 영상을 인식과정에 사용하여 실험 을 수행하였다.

그림4 그림7은 실험에 사용한 ORL 과 Yale의 얼 보였다. 인식을 위한 거리 측정은 유클리디안 거리측 정 방법을 사용하여 측정하였다.

\section{4-2 실험 결과 및 분석}

실험은 기존의 방법과의 비교를 통하여 제안한 방 법의 우수한 성능을 입증하도록 하였다. 비교는 1 차 원 주성분 분석법(1D PCA), 2차원 다중 선형 주성분 분석법과 선형판별 분석법의 결합 방법(2D MPCA + $\mathrm{LDA}), \mathrm{SVM}$ 을 적용한 방법, 웨이블릿 변환과 2차원 주성분 분석법을 결합한 방법 $(\mathrm{WT}+2 \mathrm{D} \mathrm{PCA}), 2$ 차원 주성분 분석법과 $\mathrm{SVM}$ 을 적용한 방법(2D $\mathrm{PCA}+$ $\mathrm{SVM})$ 과 본 논문에서 제안한 이산 웨이블릿 변환 후 LL 대역을 이용한 2차원 주성분 분석법을 통하여 얻 은 특징벡터를 이용하여 SVM 분류기를 적용한 방법 $(\mathrm{WT}+2 \mathrm{D} \mathrm{LDA}+\mathrm{SVM})$ 에 관하여 실험한 결과를 비교 하였다.

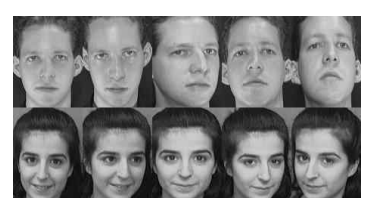

그림 4. ORL 훈련 데이터 예 Fg. 4. Examde of ORL tring data.

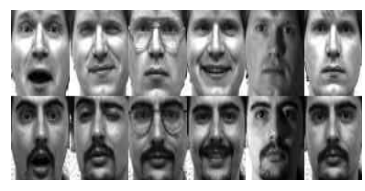

그림 6. Yale 훈련 데이터 예 Fig. 6. Example of Yale training data

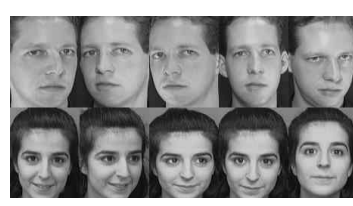

그림 5. ORL 테스트 데이터 예 Fg. 5. Exampe of ORL test cala.

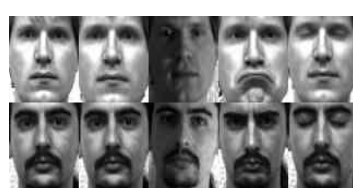

그림 7. Yale 테스트 데이터 예 Fig. 7. Example of Yale test data 


\section{4-2-1 인식률 비교 분석}

표 1는 각 방법들에 대한 ORL 데이터베이스와 Yale 데이터베이스의 인식률을 비교하였다.

웨이블릿을 수행한 다음 LL대역만을 이용하여 2 차원 $\mathrm{LDA}$ 를 수행하고 $\mathrm{SVM}$ 을 적용하는 방법은 기본 적인 1차원 $\mathrm{PCA}$ 방법보다는 각각 $9 \%$ 와 $10.7 \%$ 향상 된 인식률을, 2차원 $\mathrm{MPCA}$ 와 $\mathrm{LDA}$ 를 결합한 방법보 다 각각 $1.5 \%$ 와 $1.4 \%$ 향상된 인식률을, SVM 방법보

다는 각각 $2 \%$ 와 $4 \%$ 정도의 인식률 향상을 보였다. 또한, 웨이블릿 변환(WT)과 2D PCA를 결합한 방법 보다는 각각 $3 \%$ 와 $4 \%$ 더 우수한 인식 성능을, $2 \mathrm{D}$ $\mathrm{LDA}$ 와 SVM을 결합한 방법보다는 각각 $1 \%$ 와 $2.7 \%$ 의 인식률 향상을 보였다. 웨이블릿의 LL 대역은 에 너지가 집중되어 있는 영역으로 분산의 크기가 다른 영역에 비하여 크기 때문에 분산의 최대화를 통하여 차원을 축소하는 방법인 PCA 또는 LDA 방법에 적용 하였을 경우 효과적인 인식 성능을 보이게 된다는 것 을 확인하였다. 아울러 웨이블릿 변환을 통한 에너지 의 집중 대역을 이용하여 특징 벡터를 얻고 SVM 분 류기를 사용함으로써 인식 성능의 향상을 얻을 수 있 었다. ORL과 Yale 데이터베이스 모두 제안방법이 기 존의 방법들보다 우수한 인식률을 보임을 확인 할 수 있었다. Yale 데이터베이스의 경우 비슷한 색조톤을 갖고 있으며 비슷한 모양이 ORL 데이터베이스에 비 해서 많아 인식률이 ORL의 경우보다 낮은데, 제안한 방법을 이용할 경우 고유의 특징 을 이용하여 데이터

표 1. 인식률 비교표

Table 1. Comparison table of recognition ratio.

\begin{tabular}{|c|c|c|c|}
\hline & \multirow{2}{*}{ 인식방법 } & \multicolumn{2}{|c|}{ Database } \\
\hline & & ORL & Yale \\
\hline \multirow{5}{*}{$\begin{array}{l}\text { 기 } \\
\text { 존 } \\
\text { 방 } \\
\text { 법 }\end{array}$} & 1D PCA & $90.0 \%$ & $76.0 \%$ \\
\hline & 2D MPCA + LDA & $97.5 \%$ & $85.3 \%$ \\
\hline & SVM & $97.0 \%$ & $82.7 \%$ \\
\hline & $\mathrm{WT}+2 \mathrm{D}$ PCA & $96.0 \%$ & $82.7 \%$ \\
\hline & 2D LDA+SVM & $98.0 \%$ & $84.0 \%$ \\
\hline \multicolumn{2}{|c|}{$\begin{array}{l}\text { 제안방법 } \\
\text { (WT-LL+2D LDA+SVM) }\end{array}$} & $99.0 \%$ & $86.7 \%$ \\
\hline
\end{tabular}

의 구분이 가능하여 인식률 향상의 결과를 보였다.

\section{4-2-2 처리시간 비교 분석}

표 2에서는 ORL 데이터베이스 영상에서의 기존의 알고리즘과 제안 방법의 처리 시간을 비교하였다. 표 3 에서는 Yale 데이터베이스의 영상에서 기존 알고리 즘과 제안 방법의 처리 시간을 비교하였다. 실험에서 확인한 처리 시간은 수차례 반복 수행을 통하여 평균 을 내었다. 표에서의 전체 시간과 각각의 수행의 시 간의 합과의 차이가 있는 것은 주요 기능에 대한 수 행 시간만 표기하였기 때문이다.

이산 웨이블릿 변환을 수행한 후 2차원 LDA 방법 을 수행하는 방법은 에너지가 집중되어 있는 LL 대 역을 이용함으로써 차원을 줄여 수행하였기 때문에 처리 시간이 감소함을 확인할 수 있었다. 또한 메모 리의 효율적인 사용도 가능할 것이다. SVM의 수행 에 있어서는 학습을 통한 학습 모델의 생성과 예측을 통한 인식의 과정에서 어느 정도의 시간이 소요되었 다. PCA나 LDA를 통하여 고유의 특징벡터를 이용하 여 SVM의 과정을 수행할 경우 PCA나 LDA 방법이 차원을 축소시켜 특징 벡터를 얻는 방법이므로 더 작 은 양의 데이터를 이용하여 SVM 분류기를 사용하므 로 처리시간의 단축을 가져올 수 있으며, 특징벡터의 사용으로 인식률을 향상 시킬 수 있게 된다.

반면, 이산 웨이블릿 변환에 소요되는 시간이 차원

표 2. ORL 데이터베이스의 알고리즘 처리시간 비교 (단위: 초) Table 2. Processing time comparison for ORL Database.

\begin{tabular}{|c|c|c|c|c|c|}
\hline \multirow{2}{*}{ 인식방법 } & \multirow{2}{*}{ 인식방법 } & \multicolumn{4}{|c|}{ ORL DB } \\
\hline & & 젗ㅊ & WT & SVM & SVM \\
\hline \multirow{5}{*}{$\begin{array}{l}\text { 기 } \\
\text { 존 } \\
\text { 방 } \\
\text { 법 }\end{array}$} & 1D PCA & 6.42 & & & \\
\hline & 2D $\mathrm{MPCA}+\mathrm{LDA}$ & 9.78 & & & \\
\hline & SVM & 10.15 & & 4.84 & 5.31 \\
\hline & WT +2D PCA & 5.53 & 2.80 & & \\
\hline & 2D LDA+SVM & 0.63 & & 0.36 & 0.27 \\
\hline \multicolumn{2}{|c|}{$\begin{array}{l}\text { 제안방법 } \\
\text { (WT-LL+2D DA+SVM) }\end{array}$} & 3.16 & 2.80 & 0.21 & 0.13 \\
\hline
\end{tabular}


표 3. Yale 데이터베이스의 알고리즘 처리시간 비교(단위: 초) Table 3. Processing time comparison for Yale Database.

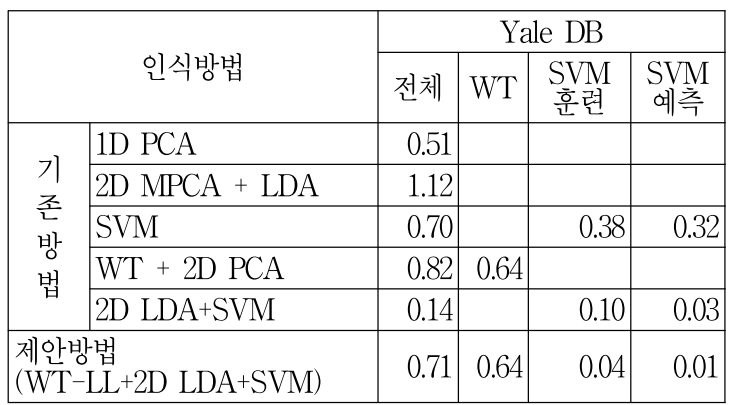

축소를 통한 특징벡터를 이용하여 SVM을 수행한 경 우 전체 처리시간에서 차지하는 부분이 크게 되어 전 체 처리 속도의 대부분이 소요되었음을 확인하여 일 부 방법들 보다는 처리시간이 증가하였으나, 인식률 향상과의 트레이드-오프 관계를 고려해 볼만 하다.

\section{V. 결 론}

본 논문에서는 웨이블릿 변환의 특성을 이용한 얼 굴인식 방법에 대하여 제안하였다. 먼저 이산웨이블 릿 변환을 수행하여 에너지의 집중도가 높은 LL 대역 을 선택하여 2차원 피셔판별분석(LDA)를 수행하여 차원을 줄여 특징벡터를 얻고 최적의 분류기법인 $\mathrm{SVM}$ 을 이용한 얼굴인식 시스템을 제안하였다. 이 방 법의 경우 에너지의 집중도가 높은 LL 대역을 이용함 으로써 분산의 최대화를 통하여 차원을 줄임으로 인 식률의 향상에 도움을 얻었다. 또한 LL대역을 얼굴인 식의 데이터로 이용하기 때문에 입력 데이터부터 차 수를 줄일 수 있어 메모리 활용이나 처리할 데이터양 의 감소로 처리 시간에 효율성을 높일 수 있었다. 또 한 2차원의 데이터 변형없이 LDA를 수행함으로써 손 실을 줄여 인식률을 향상이 가능하였다. 특징벡터를 이용하여 SVM을 수행할 경우는 고유의 특징을 잘 나 타낼 수 있게 되어 클래스 분류에 있어서 더 효율적인 분리가 가능해진다.

제안한 방법은 기존의 방법들과의 비교를 통하여 우수성을 입증하였다. 시뮬레이션은 Matlab을 이용하 였고, 기존의 1 차원 $\mathrm{PCA}$ 방법보다 ORL 데이터베이스 의 경우는 약 $9 \%$, Yale 데이터베이스의 경우는 약
$10.7 \%$ 의 인식률 향상을 보였다. 또 SVM 방법보다는 ORL은 약 $2 \%$, Yale은 $4 \%$ 의 인식률 향상을 보였다. 2 차원 LDA와 SVM을 이용한 방법보다도 ORL은 약 $1 \%$, Yale은 약 $2.7 \%$ 의 인식률이 향상됨을 확인하였다. 이산 웨이블릿의 특징을 이용한 얼굴인식 방법에 서는 LL 대역을 이용하여 처리 시간의 단축과 차원의 축소에 효율적으로 대응할 수 있었다. 이 방법에서 입 력데이터의 크기가 작은 저해상도의 영상을 이용하여 인식을 수행할 경우 웨이블릿 변환 후의 LL 대역의 크기 또한 더 작아지게 되므로 차원 축소로 인한 인식 률 저하의 문제가 발생할 수 있다. 또 웨이블릿 변환 이 전체 처리속도에 미치는 영향이 커지므로 고속의 웨이블릿 변환방법과 인식률 개선에 대한 적절한 해 결방법에 대하여 부가적인 연구가 필요하다. 이 방법 의 경우 인식률은 향상되었으나 다차원의 데이터를 이용한 특징 벡터를 얻어야 하는 계산의 복잡성으로 인하여 처리 시간의 증가를 가져왔다. 차후에 처리시 간을 더욱 감소시키기 위한 연구가 필요하다.

\section{감사의 글}

본 논문은 2012년도 교내학술연구비 지원에 의해 연구되었음.

\section{Reference}

[1] G. Shakhnarovich and B. Moghaddam, "Face Recognitio $\mathrm{n}$ in Subspaces," Handbook of Face Recognition, Eds. Stan Z. Li and Anil K. Jain, Springer-Verlag, Dec. 2004.

[2] R. Chellappa, C. L. Wilson, and S. Sirohey, "Human and Machine Recognition of Faces: A Survey," Proceedin gs of the IEEE, Vol. 83, Issue 5, pp. 705-740, May 1995.

[3] M. Turk and A. Pentland, "Eigenfaces for Recognition," Journ al of Cognitive Neurosci- ence, Vol. 3, No. 1, pp.72-86, 1991.

[4] P. N. Belhumeur, J. P. Hespanha, and D. J. Kriegman, "Eigen faces vs Fisherface : Recognition Using Class Specific Linear Projection," IEEE Trans. Pattern Analysis and Machine Intel ligence, Vol. 19, №. 7, pp. 711-720, July 1997.

[5] J. Yang, D. Zhang, et al, "Two-dimensional PCA: A New Approach to Appearance-based Face Representation and 
Recognition," IEEE Trans. Pattern Analysis and Machine Intelligence, Vol. 26, No. 1, pp. 131-137, Jan. 2004.

[6] M. Li and B. Yuan, "2D-LDA: A Statistical Linear Discriminant Analysis for Image Matrix," Pattern Rec ognition Letters, pp. 527-532, 2005.

[7] L. Sirovich and M. Kirby, "Low-dimensional Producer for Characterization of Human Faces," J. Opt. Soc. Ame r., Vol. 4, pp. 519-524, 1987.

[8] M. Kirby and L. Sirovich, "Application of KarhunenLoeve Producer for the Characterization of Human Faces," IEEE Trans. Pattern Analysis and Machine Intelligence, Vol. 3, No. 1, pp. 103-108, Jan. 1990.

[9] J. Yang, D. Zhang, X. Yong, and J. Y. Yang, "Two-dime nsional discriminant transform for face recognition," Pat tern Recognition, Vol.38, No.7, pp. 1125-1129, 2005.

[10] X. Y. Jing, H. S. Wong, and D. Zhang, "Face recogn ition based on 2D Fisherface approach," Pattern Reco gnition, Vol.39, No.4, pp. 1125-1129, 2005.

[11] M. Li and B. Yuan, "2D-LDA: A Statistical linear discriminant analysis for image matrix," Pattern Reco gnition Letters, pp. 527-532, 2005.

[12] H. Xiong, M. N. S. Swamy, and M. O. Ahmad, "Two-dimensional FLD for face recognition," Patter n Recognition, Vol.38, No.7, pp. 707-710, 2006.

[13] "LibSVM" http://www.csie.ntu.edu.tw/ cjlin /libsvm/

[14] "Olivetti-ATT Database of Faces," http://www.cl.cam.ac.uk/ research/dtg/ attarchive/facedatabase.html

[15] "Yale Face Database," http://cvc.yale.edu/ projects/ yalefaces/yalefaces.html
박 경 준 (Kyung-Jun Park)

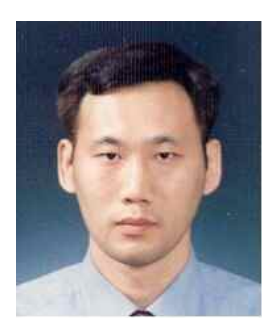

1999년 2월 : 서울과학기술대학교 전자공학과(공학사)

2001년 2월 : 광운대학교 전자통신 공학과(공학석사)

2011년 2월 : 광운대학교 전자통신

공학과(공학박사)

2011년 8월 현재 : (주) 마크애니 미디어

솔루션 사업부 과장

관심분야 : 영상처리, 임베디드 시스템

서 석 용 (Seok-Yong Seo)

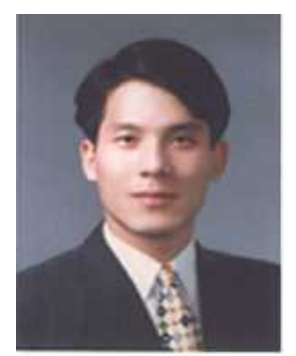

1996년 2월 : 관동대학교 전자통신 공학과(공학사)

2000년 8월 : 광운대학교 전자통신 공학과(공학석사)

2012년 2월 : 광운대학교 전자통신 공학과(공학박사)

2013년 9월 현재 : 경민대학교

정보통신과 조교수

관심분야: JBIG2, H/W-S/W co-design, Watermarking

고 형 화 (Hyung-Hwa Ko)

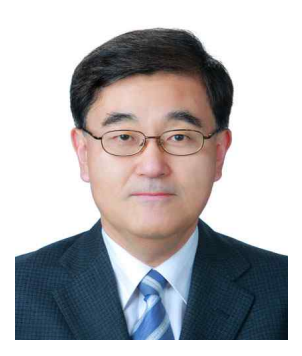

1979년 2월 : 서울대학교 전자 공학과(공학사)

1982년 2월 : 서울대학교 전자 공학과(공학석사)

1989년 2월 : 서울대학교 전자

공학과(공학박사)

1985년 3월 현재 : 광운대학교

전자통신공학과 교수

관심분야 : H.264, JBIG2, H/W-S/W co-design, HEVC, Watermarking 